\title{
ORBITAL FOREIGN BODY SIMULATING A MALIGNANT MELANOMA*†
}

\author{
BY
}

\author{
C. N. BANKS
}

Lately House Surgeon to the Eye Department, St. Bartholomew's Hospital

THE case recorded here presented as an epibulbar melanoma, but there was a history of trauma 3 months previously and at operation the tumour was found to be a foreign body surrounded by old blood clot.

\section{Case Report}

A man aged 52 was admitted to hospital on March 25, 1965, with a history of having been accidentally struck in the nasal side of the right eye by a billiard cue.

Examination.- - He was found to have a retrobulbar haemorrhage spreading forward beneath the conjunctiva, his pupil was semi-dilated and fixed, he had no perception of light, and there was no red reflex. $X$ rays showed no evidence of fractures or of a foreign body in the orbit.

Treatment.-Chymoral tablets and gutt. chloramphenicol were given and a week later he was found to have some macular oedema and the visual acuity was 6/24. After a further week the visual acuity had improved to $6 / 6$, but about this time he began to develop a paresis of the oculomotor nerve on the right, with diplopia, divergence of the eye, and ptosis. No foreign body or tumour could be seen at this stage.

Progress.-On June 8 he was seen in the Eye Department of St. Bartholomew's Hospital, where the presence of an oculomotor palsy was confirmed. However, when the upper lid was lifted, a deeply pigmented mass with a paler centre was seen lying upon the sclera between the adjacent borders of the lateral and superior rectus muscles (Figure). No intra-ocular tumour could be seen, and a provisional diagnosis of epibulbar melanoma was made. The patient was admitted for excisional biopsy.

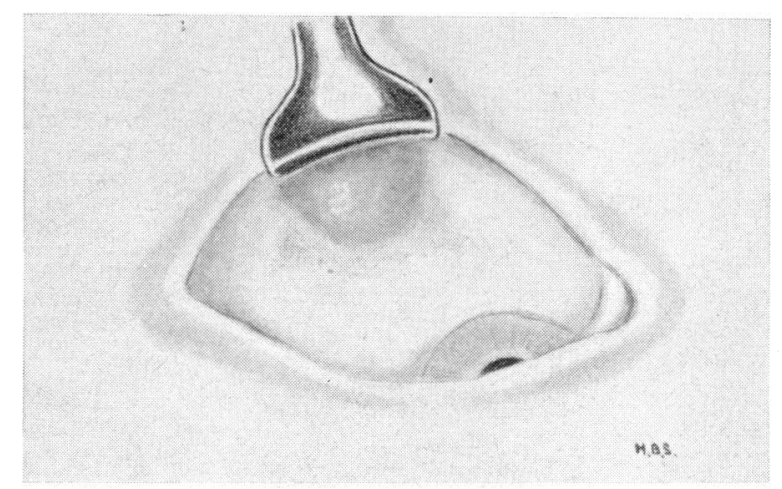

FIGURE.-Drawing of right eye, showing the "tumour". The globe is turned down to the left and the upper lid is held back with a retractor.

* Received for publication March 9, 1966,

† Address for reprints: Moorfields Eye Hospital, City Rd., London, E.C.1. 
Operation.-The tumour was exposed through a conjunctival incision, and its centre was found to be harder than expected for a melanoma. After removal of the peripheral debris, a flat, circular foreign body, $10 \mathrm{~mm}$. in diameter and $3 \mathrm{~mm}$. thick, was removed from the surface of the sclera. The wound was closed and the post-operative progress was uneventful.

Histological Examination.-The pigmented debris was shown to be a foreign body giant cell type of granulomatous reaction with old and recent haemorrhage but no evidence of any neoplasm.

\section{Comment}

The tip of the billiard cue had been lost at the time of injury and could not be found, despite diligent searching. It had evidently lodged in the orbit, but it was 3 months before its presence was declared, and then it showed as a tumour with pigmentation due to a resolving haematoma. Epibulbar melanoma is extremely rare. Ash (1950) recorded only 67 in a series of 1,120 epibulbar tumours, and there was a past history of trauma in seventeen of them. In the case described above the appearance at presentation belied the history and it is a reminder of George Peele's warning in An Old Wives Tale that "Things that seem are not the same".

I am grateful to Mr. H. B. Stallard for encouraging me to record this case and for lending me the drawing. I should also like to thank the general practitioner and surgeon who first saw the case for providing me with the details of the initial findings and management.

\section{REFERENCE}

Ash, J. E. (1950). Amer. J. Ophthal., 33, 1203. 